REsumo
Este artigo se embasa no tra-
balho e teoria de Françoise
Dolto. Tivemos como objetivos
compreender os pressupostos
básicos de sua teoria; caracteri-
zar as intervenções do psicana-
lista na análise com crianças; $e$
exemplificar seu método através
do recorte das principais inter-
venções realizadas no Caso
Dominique e no caso
Bernadette. Como resultado,
constatamos que Dolto traba-
lhava com maestria o fenômeno
da transferência e as situações
de interpretação; providenciava
a oferta de recursos adequados
à condição da criança; condużia
o trabalho com os pais permi-
tindo a efetivação do sentimento
de confiança neles, em aderirem
ao tratamento analitico de seus
filhos.
Descritores: psicanálise com
crianças; Françoise Dolto;
transferência; interpretação; tra-
balho com pais.

\section{A PRÁTICA PSICANALÍTICA DE FRANÇOISE DOLTO A PARTIR DE SEUS CASOS CLÍNICOS}

\author{
Vanessa Tramontin da Soler \\ Leda Mariza Fischer Bernardino
}

\section{Introdução}

$\mathbb{E}$ reud, apesar de ter argumentando que a psicanálise deveria ser ampliada ao longo dos anos, apresentava algumas dificuldades para a análise com crianças (Freud,1996a). Sabemos hoje que essas dificuldades estão superadas, e que a análise com crianças é possível. Melanie Klein (1981), Anna Freud (1971), Donald W. Winnicott (1984), Maud Mannoni

Mestranda em Psicologia pela Universidade Federal do Paraná (UFPR), Curitiba, PR, Brasil.

Psicanalista. Docente da Faculdade de Psicologia da Pontifícia Universidade Católica do Paraná (PUCPR), Curitiba, PR, Brasil. 
(1999) e Françoise Dolto (1980) demonstraram com o seu trabalho e suas teorias a importância de voltarmos nossa atenção para o trabalho psicanalítico com crianças. Cada um deles, ao seu modo, construiu uma maneira de conceber a criança e consequentemente de analisá-la.

Segundo Bernardino (2004) a análise com crianças necessita de uma teorização própria, pois a demanda, a transferência e o fim de análise vão ser permeados pelas vicissitudes de um sujeito ainda em constituição. Outra questão particular da análise de crianças trata de que, além do desejo da criança, há o desejo dos pais, desejo que os próprios não conhecem, mas que se faz presente no processo de análise:

Vai estar em jogo lidar com a presença destes pais que, mesmo não entrando fisicamente na sessão do filho ... continuam se manifestando: seja nos atrasos para trazer o filho à sessão, ou mesmo nas faltas que o fazem ter, seja nos diversos trâmites que impõem ao pagamento, e até na interrupção abrupta do tratamento do filho (Bernardino, 2004, p.65, itálico do autor).

A análise com crianças difere da análise com adultos também pelo método empregado: no atendimento psicanalítico à criança a associação livre não é possível, sendo assim é utilizado o método do brinquedo, da conversação e do desenho (Dolto, 1988). Frente a essas diferenciações, fica evidente a necessidade de uma teorização própria sobre a análise de crianças.

No presente trabalho, focamos nossa atenção sobre a teoria de Françoise Dolto. No campo da psicanálise, a teoria construída por Dolto e a prática por ela realizada se firmaram como uma obra revolucionária para a sociedade. Fora do campo da teoria, ela "é uma exploradora, descobrindo a infância como outros descobrem um continente" (Halmos, 1989, p.74). Sua teoria ofereceu um novo lugar às crianças, um lugar próprio. "Ouvindo as crianças, em lugar de falar delas e em seu lugar, Françoise Dolto fez uma ruptura e um escândalo" (Halmos, 1989, p.83).

$\mathrm{O}$ atendimento psicanalítico iniciado por Françoise Dolto, na década de 30, foi a primeira possibilidade de tratamento analítico na França com crianças ditas anormais que apresentavam distúrbios nervosos ou de caráter. Dolto, juntamente com Sophie Morgenstern foram, nessa época, as duas únicas analistas na França a mostrar interesse e competência face aos problemas da infância (Manonni, 1986). 
Em sua prática, Dolto trata a criança como uma pessoa autônoma e responsável, orienta-se através da interrogação face ao desejo da criança e permanece atenta às diferentes posições da criança, nos momentos de tensões conflitivas em que ela se encontra (Manonni, 1986).

Diante de toda a contribuição de Françoise Dolto ao campo da psicanálise de crianças, tivemos como objetivo, neste trabalho, compreender os pressupostos básicos da teoria de Françoise Dolto; caracterizar, segundo ela, as intervenções do psicanalista na análise de crianças; e exemplificar o método de Dolto através do recorte das principais intervenções realizadas em $O$ caso Dominique (Dolto, 1981) e no "caso Bernadette" (Dolto, 1996).

Esse estudo foi realizado através de pesquisa bibliográfica. Foram analisados o "caso Dominique" (Dolto, 1981) e o "caso Bernadette" (Dolto, 1996) atendidos por Dolto, por se tratarem de casos que receberam uma descrição minuciosa, devido à necessidade da presença detalhada das intervenções para a realização desta pesquisa. Para a análise dos casos, utilizaremos a Análise do Discurso, tal como proposta por Marilene Guirado (1995).

Através da leitura e da análise dos discursos, foram identificadas algumas categorias comuns entre eles. Essas categorias foram agrupadas da seguinte forma: o manejo da transferência; as situações de interpretação; 
a oferta de recursos expressivos; o trabalho com os pais.

\section{A clínica de Françoise Dolto}

Em sua teoria e prática, Françoise Dolto propôs um lugar novo às crianças ouvindo-as, em lugar de falar delas, ou falar por elas (Halmos, 1989, p.83). Posicionamento que tem extrema relação com a concepção de criança em que a autora se pautava em sua prática como médica e psicanalista. A criança, para ela, é um sujeito, e não encarada como um 'mini-adulto', ela compartilha as vicissitudes e as alegrias da vida. Assim,

como o adulto, ela ama, odeia, sofre e goza; como ele, a criança pode falar em seu nome, ela compreende tudo, desde a aurora de sua vida. Colérica, anoréxica, doente ou mau aluno, a criança não é testemunha de um defeito de fabricação ou de uma avaria em seu desenvolvimento, mas de um sofrimento que ela tenta fazer entender como pode (Halmos, 1989, p.83).

Desde Freud (Freud, 1996b, p.329) sabemos que o sintoma "surge ali onde o pensamento recalcado e o pensamento recalcador conseguem juntar-se na realização do desejo". O sintoma denota a presença de um processo patológico, é um sinal e um substituto de uma satisfação instintual que se manteve em estado jacente, é também uma conseqüência do pro- cesso de repressão (Freud, 1996c, pp. 91-95). O sintoma, portanto, é a busca de uma conciliação entre a satisfação pretendida e a proibição da realização dessa satisfação.

Segundo Dolto, na primeira infância, os sintomas da criança "tratam-se de distúrbios reativos a dificuldades parentais, a distúrbios entre os irmãos ou do clima inter-relacional ambiente" (Dolto, 1980, p. 14). Quando se tratar de distúrbios posteriores da infância ou da adolescência, eles podem dever-se aos conflitos da criança frente às exigências do meio social e das provações do complexo de Édipo normal. Alguns sintomas são aceitos positivamente pelo meio social, que muitas vezes não verifica tais comportamentos como sintomáticos, mas que podem ser patológicos para o sujeito e são sinais de neurose infantil.

Para Dolto e Nasio (2008) quaisquer que sejam os problemas da criança,

a hipótese geral é de que ela sofre de uma angústia de culpa inconsciente cujos sintomas são ao mesmo tempo a prova e o recurso que sua natureza entregue a si mesma encontrou para canalizar essa angústia e impedir a criança de destruir mais gravemente o equilíbrio de sua saúde. (p.77)

Dolto propõe a hipótese de que a criança adoece do inconsciente dos pais, "uma criança herdeira de nossas dívidas de adultos, uma criança sintomática do que permaneceu atado às gerações que a precederam" (Cifali, 1989, p.65). 
Françoise Dolto se coloca à escuta desse sintoma. Não é apenas com a criança isolada que ela trabalha. A interrogação inicial é com a dinâmica familiar. Por vezes, nada pode ser feito enquanto a criança é tomada como objeto por um ou outro dos pais, "é quando os pais se tornarem atentos à 'necessidade de realização autônoma de seu filho' que este terá uma oportunidade de abrir-se 'ao risco da análise"” (Manonni, 1986, p.135).

A atuação da psicanalista diante do discurso e da dinâmica familiar é de atenção e intervenções. Diferente de Melanie Klein (1969) que focava sua intervenção na criança, e pouco contato estabelecia com os pais, Françoise Dolto não atua com a criança separadamente. Realiza as entrevistas preliminares com os pais, na presença da criança, comentando as palavras parentais pronunciadas diante da criança, dando a entender que há uma má compreensão de sua parte. Do mesmo modo, Françoise Dolto não hesita em dar conselhos aos pais, conselhos que poderíamos qualificar como educativos, "trata-se, de fato, de intervenções que se apóiam nos 'pressentidos' precoces fundamentais, cujo efeito passado volta à cena no presente (Édipo, castração)" (Manonni, 1986, p.135).

A utilização do discurso familiar por Dolto visa um "desvelamento catártico. Françoise Dolto não se situa como terapeuta de família, mas sim como uma analista a serviço do jovem paciente trazido pela família para atendimento" (Manonni, 1986, p.136, itálicos do autor). Para Dolto, a intervenção analítica não consiste na explicação de um complexo seja de Édipo ou de castração, mas em um trabalho focado no drama revivido na transferência.

Segundo Dolto (1988), no atendimento psicanalítico à criança, a primeira entrevista deve ser realizada primeiramente com a mãe ou com os pais, acompanhados da criança. Esta entrevista com os pais não deve ser realizada depois da conversa privada com a criança. A orientação é de que a criança faça um desenho ou outro trabalho, instalada em uma mesa, e ao se falar com os adultos, preste-se atenção ao modo como a criança reage.

Cifali (1989) expõe que Dolto não poupava críticas em relação à terapêutica que coloca a criança numa situação de intimidação ou de consumo de remédios, que evitem que a criança expresse seu desejo, a seu modo.

Finda a entrevista com os pais, Dolto oferece a eles uma breve opinião, porém não da mesma maneira que eles encaram a situação: “já antes de uma informação mais ampla, não aceitamos a alternati- 
va proposta: doença ou maldade ... a primeira dessas interpretações anula toda a responsabilidade da criança, a segunda atribui-lhe toda a responsabilidade" (Dolto, 1988, p.134-135). Qualquer uma dessas pontuações, a de eximir ou de responsabilizar totalmente a criança, inviabiliza a análise, e, como argumenta Dolto (1988), tende a fixar ainda mais a criança no círculo vicioso de seus sintomas neuróticos.

Dolto propõe que após a devolutiva aos pais, solicite-se que a criança fique a sós com o analista. Ela também sugere que, ao se trabalhar com a criança, devemos usar o método do brinquedo, da conversação e do desenho, pois o método da associação livre não é possível. Sobre o desenho a autora defende que através deles entramos "no âmago das representações imaginativas do paciente, da sua afetividade, do seu comportamento interior e do seu simbolismo" (Dolto, 1988, p.132).

Através do brinquedo, da conversação, do desenho e da modelagem, a criança exprime seu contexto cotidiano, medos e angústias. Dolto e Nasio (2008, p.79) expõem que os recursos que servem para a psicoterapia variam muito dependendo do psicoterapeuta. Podem ser utilizados fantoches, cubos, miniaturas de objetos do cotidiano, modelagem, pintura, lápis de cor. Todos esses são utilizados com o mesmo objetivo: fazer com que a criança verbalize seus afetos, expresse os conflitos e tensões. 
Dolto utiliza lápis de cor e modelagem.

Dolto não ofertava brinquedos à criança,

porque ela pode fazer sozinha. É muito melhor. Em vez de dar-lhe coisas que são ... projetivas, pois ela projeta qualquer coisa em um brinquedo, espera-se aquilo que ela mesma vai projetar, a partir de matérias-primas, em desenho ou em modelagem. (Dolto \& Roudinesco, 1989, p.11, itálico do autor)

Segundo Dolto, não convém realizarmos uma interpretação direta do desenho, ele servirá mais para orientar as conversações. Estas, as conversações, devem provocar discursos variados das crianças, portanto, ao ser questionado por alguma curiosidade do paciente, o analista não deve responder, mas intervir no sentido de fazê-lo falar, questionando-o, por exemplo, sobre o que pensa do assunto. Durante a conversação "procuramos escutar, olhar, observar, sem deixar escapar o mínimo detalhe, os gestos, as expressões, mímica, palavras, lapsos, erros e desenhos espontâneos". Do mesmo modo,

não procuramos inculcar na criança o nosso modo de ver mas, tão-somente, apresentarlhe seus próprios pensamentos inconscientes sob o aspecto real. Tampouco falamos uma linguagem 'lógica' que vise ferir a inteligência da criança, que ... ainda não é lógica; queremos falar ao seu inconsciente - que jamais é 'lógico' em pessoa alguma - e é por isso que empregamos, muito naturalmente, a linguagem simbólica e afetiva, que é a dela e a afeta diretamente. (Dolto, 1988, pp. 132133) 
Françoise Dolto traduz para a criança, na língua dela, o que a analista pensa dos efeitos que a situação familiar produziu na criança. Ela propõe uma "construção, isto é, um pedaço da história que escapa ao sujeito, a partir do que a criança encontra palavras com que falar, e através das quais surge, sem que a criança saiba, uma verdade" (Manonni, 1986, p.135, grifo do autor).

Com frequência uma sessão pode ocorrer em que a criança falou e desenhou e o analista apenas escutou. Outras vezes há a conversação em que os discursos variados da criança são provocados, porém, segundo Dolto (1988, p. 134), intelectualmente, quase nada de novo é proporcionado à criança. A intervenção do terapeuta deve ser a mínima possível, fazendo-a apenas para permitir a expressão mais acabada e emocionada das dificuldades e conflitos que a criança tem, seja com ela própria ou com os que a cercam (Dolto \& Nasio, 2008, p.79).

Essa relação entre a criança e o psicanalista é possibilitada pela situação da transferência, "situação de adesão afetiva ao psicanalista, que se converte num personagem, e dos mais importantes, do mundo interior da criança, durante o período de tratamento" (Dolto, 1988, p.133), a facilidade com que a criança fornece conteúdos relativos aos sonhos, segredos, suas faltas e a confiança a que atribui ao analista são a base da ação terapêutica. Através da transferência, portanto, o analista pode estudar os mecanismos inconscientes do indivíduo, seu comportamento frente ao psicanalista, participando daquilo que ele, o paciente, tem em relação à outra pessoa (Dolto, 1988, p.147).

É frequente os sintomas cessarem logo que a análise é iniciada. Dolto nos adverte de que essa é apenas uma cura aparente e que pode ser efeito da transferência. A cura, de fato, só é assegurada se o analisado

além do desaparecimento duradouro dos seus sintomas, 'viver interiormente em paz'. Isso quer dizer que reage às dificuldades reais da vida sem angústia, adotando uma atitude espontaneamente adaptada às exigências de uma ética em concordância com o meio em que escolheu e às suas próprias; e tudo isso permitindo às suas pulsões instintivas traduções adequadas (descargas libidinais em qualidade e em quantidade suficientes) que assegurem a conservação do equilíbrio adquirido. (Dolto, 1988, p.149)

A transferência também ocorre na relação com os pais. Em decorrência dela outros são os fenômenos que podem ocorrer no 
atendimento clínico à criança. Há tratamentos que provocam aflição em um dos pais que fica abalado demais com a melhora do filho. Esses pais que não suportam a mudança dos filhos também precisam de ajuda. A aflição em um dos pais pode gerar resistência da criança à análise, visto que para ela, esse é um trabalho penoso. A criança, frente a essa situação, pode criar, com suas palavras e comportamentos, justificativas para os pais suspenderem seu tratamento, sem a concordância do terapeuta. Este, por sua vez, também não tem interesse em manter o paciente nessas condições. Porém, nem sempre um tratamento que é interrompido antes de seu término ou mesmo um tratamento curto são dramáticos, “a vantagem consiste em ficar menos vulnerável aos desafios que virão, ainda que nem todas as sequelas dos desafios da pequena infância tenham sido apagadas" (Dolto \& Nasio, 2008, p.83).

\section{Casos clínicos}

Para verificar se as características apresentadas sobre a clínica de Françoise Dolto estão presentes nos casos que receberam acompanhamento psicanalítico por ela, faremos a exposição de recortes de dois casos por ela atendidos, o Caso Dominique (Dolto, 1981) e o Caso Bernadette (Dolto, 1996), a partir das categorias de análise: o manejo da transferência; as situações de interpretação; a oferta de recursos expressivos; o trabalho com os pais.

Iniciemos com o "caso Bernadette" (Dolto, 1996). A primeira sessão foi com a mãe e a menina. Bernadette estava com cinco anos e meio, apresentava aparência de retardo mental, falava com a voz monocórdica, gritando como se fosse surda, a mão e a perna esquerda tinham os movimentos comprometidos, caminhava arrastando a perna e o braço ficava dobrado, com a mão sobre o antebraço. Bernadette sofria de anorexia mental, em que a recusa em comer era extrema, e quando era forçada a fazê-lo, os alimentos eram parcialmente vomitados. No primeiro contato com a mãe, além dessas informações sobre a solicitação de atendimento, Dolto faz um apanhado geral sobre a vida de Bernadette. Questiona mais sobre o sintoma de anorexia, os membros da família, e sobre as pessoas com quem Bernadette se relaciona.

Após a primeira entrevista, Dolto expõe que diante da organicidade da anorexia, que ocorria desde o nascimento, a analista não acreditara que a psicanálise pudesse ter serventia. A mãe de Bernadette fizera análise por 10 anos e ouvira dizer que nos Estados Unidos algumas crianças com dificuldades semelhantes eram tratadas pela psicanálise, e assim ela insistiu para que Dolto realizasse pelo menos algumas sessões (Dolto, 1996, pp.115117). Está presente aqui uma das ca- 
racterísticas que distinguem a análise com crianças: o desejo dos pais. Além da demanda ser realizada por eles, há a solicitação dessa mãe que, mesmo recebendo a negativa da analista, insiste na realização do trabalho analítico. Está em ação, portanto, a transferência da mãe para com a analista.

$\mathrm{Na}$ primeira sessão a sós com Bernadette, a menina faz um desenho abstrato, diz que é um pinheiro, que chama de pinheirar. Uma constatação que a analista faz, é de que essa é uma das formas da chamada linguagem esquizofrênica, em que os substantivos ganham a dinâmica e a ação dos verbos.

A intervenção da analista não foi só no sentido de colocar Bernadette a falar sobre seu desenho, fatos do dia a dia são incluídos na sessão. A mãe da menina precisaria se ausentar, por motivo de viagem. A analista comentou isto com Bernadette, que se mostrou encantada com a idéia da ausência da mãe. Ao mesmo tempo em que parecia querer o pai só para si, apresentou tamanha crise de angústia que não conseguia comer nada sem vomitar imediatamente, depois que a mãe foi viajar (Dolto, 1996, p. 118). O pai lhe deu a ideia de escrever uma carta para a mãe, e logo ela conseguiu comer. Assim ele procedia a cada vez que Bernadette manifestava angústia ao comer.

Nas sessões que se seguiram, Bernadette concluiu que quando sua mãe não estava, ela comia melhor. No retorno da mãe, a menina diz que ela não quer que a filha coma, que é má, mas que não foi ela própria que disse isso, e sim 'a macaca'. Nas sessões posteriores, a menina relata que agora a macaca é uma menina, que é muito má, e por gostar tanto de Bernadette, quer entrar nela, assim tenta se aproveitar do momento em que ela come, para ser comida junto com as outras coisas, e caso Bernadete a coma, transformar-se-á em macaca. Todos os seus desenhos passam a ser maus ou feios, na escola torna-se malvada e se mostra mais inadaptada do que no ano anterior.

Dolto tem a ideia, diante desse quadro narcísico em que a afetividade está marcada pelo sinal negativo, de inserir um outro recurso na análise de Bernadette: a boneca-flor. Essa ideia surge através da percepção que a psicanalista faz, em sua clínica com adultos e crianças, de que o interesse depositado em flores e a identificação com uma flor sempre acompanham o quadro clínico de narcisismo. Quando, então, a mãe de Bernadette relatou que a menina não tinha mais interesse em suas bonecas e animais, Dolto expôs que talvez ela tivesse interesse em uma boneca flor, a menina gostou da ideia. Dolto passa as instruções para a mãe confeccionar a boneca: ela deveria ser totalmente revestida de tecido verde, que não tivesse rosto, mas sim uma margarida artificial no lugar da cabeça, as roupas deveriam evocar tanto o feminino quanto o masculino, ou seja, calças e saia, tecidos rosa 
e azul. Novamente entra em cena o trabalho dos pais no atendimento a Bernadette.

$\mathrm{Na}$ próxima sessão, Bernadette conta que a boneca-flor se chama Rosine, que ela é má e horrível, e que desde que chegou em sua casa, tudo tem sido um inferno. Assim, a menina projetou toda sua atitude nessa boneca, e a partir disso, pôde falar do que se passava (Dolto, 1996, p. 121). Bernadette diz que Rosine é má, mas que ser má para ela se chama ser boazinha, porque ela tem um braço e uma perna que não funcionam, essa "é a maneira dela de ser boazinha, de fazer mal para os outros. Ela não é má, ela está doente; você vai cuidar dela" (Dolto, 1996, p. 122), e antes de ir embora, deixa Rosine com Dolto. Este é o momento em que a transferência pode ser mais constatada.

Segundo a mãe de Bernadette, após a confecção da boneca-flor e da entrega dela para Dolto, Bernadette se transformou. Nessa sessão, a menina desenha três margaridas, ela própria, a mãe e o pai. Logo após pergunta sobre sua boneca-flor, Dolto a retira do armário e diz que, mesmo tendo cuidado muito bem dela, é Bernadette que deve dizer como ela está, afinal não há ninguém como uma mãe para conhecer seu filho. Bernadette faz uma cena de conversação com a boneca-flor, cochicha em seu ouvido, e a escuta falar, dizendo depois: "Ela está curada, o braço e a perna dela funcionam muito bem, você cuidou muito bem dela". 
No encontro posterior, os pais contam que a menina solicitou que eles e a empregada assistissem a uma cerimônia que ela havia preparado que consistia no julgamento da macaca, representada por uma figura de sua arca de Noé, em quem ela investia seu ódio e que considerava responsável por seu impedimento de comer e viver. Após dançar em volta da macaca com muitos movimentos, destruiu a figura com pontapés, utilizando-se tanto da perna boa quanto da que possui limitação de movimento. Quando percebeu que não conseguira destruir a macaca por completo, chamou o pai para terminar o trabalho. Os pais se mantiveram atentos, e quando solicitado o pai auxiliou a destruir a macaca (Dolto, 1996, p.126). Novamente, constatamos a participação dos pais no tratamento de Bernadette.

Ao longo da leitura do caso Bernadette, verificamos que a atuação de Dolto com a menina é mais no sentido de colocá-la a falar, utilizando-se da oferta dos recursos expressivos e da transferência para que ela falasse de suas fantasias. Momentos de interpretação são pouco empregados. Dolto utiliza as interpretações como base nas suas intervenções, porém não as comunica a Bernadette. Segue um exemplo. Quando Bernadette chega ao consultório relatando que a boneca é má, Dolto questiona se a menina sabe o porquê dela ser má, e Bernadette responde que "é por causa de um homem que tinha um bastão e que deu a ela ideias ruins: um homem engraçado que tinha cara de lua". Com o conteúdo de todas as sessões, Dolto conclui que este homem é o pai de Bernadette, e que ao emprestar suas fantasias à boneca, a menina pode assim falar dela. Essa interpretação não é comunicada à menina, nem tampouco é feito um questionamento que remeta a seu pai, mas Bernadette é incentivada a falar no momento em que Dolto questiona: "Foi só esse homem que deu ideias ruins a ela?" (Dolto, 1996, p.121).

Os recursos utilizados na análise de Bernadette foram: o desenho, a conversação, a modelagem e a boneca-flor. O pai de Bernadette se utilizou da escrita de cartas para auxiliar no apaziguamento da angústia da filha, possibilitando que ela se alimentasse. Neste caso, o trabalho com os pais foi de fundamental importância, sendo que eles, pai e mãe, tiveram uma participação essencial no processo de análise da filha, o pai pedindo que a filha escrevesse cartas à mãe, e a mãe solicitando o tratamento e produzindo a boneca-flor, recurso essencial para esta análise e ambos par- 
ticipando da cena de julgamento da macaca, sem rejeitar este ato da filha, inclusive apoiando-a, quando solicitado.

O próximo caso que tomaremos como instrumento de discussão é o "caso Dominique".

Dominique Bel chega para atendimento com sua mãe. Após recebê-los, Dolto solicita que ele vá preparar modelagens na sala de espera. O garoto está com 14 anos, a mãe procura atendimento para diagnosticá-lo e para receber orientação sobre a colocação dele em escola em regime de internato (Dolto, 1981, p.13). Ele tem a aparência de sua idade. É esguio, "não se conserva ereto, mas um pouco à maneira de um primata. $\mathrm{O}$ seu sorriso é estereotipado e a voz 'açucarada' ... está inteiramente desorientado no tempo e no espaço" (Dolto, 1981, p.14). Aprendeu a ler, quanto à aritmética nada entende, mas repete constantemente as tabuadas. Não tem amigos, tampouco inimigos. Adora desenhar. Dominique passa o tempo desenhando figuras estereotipadas que repete há vários anos sobre aviões e automóveis.

Dominique é o segundo de três filhos. O mais velho chama-se Paul-Marie e está com 16 anos. A mais nova é Sylvie, dois anos e nove meses mais nova que Dominique. Com o nascimento da irmã caçula, Dominique manifestou fortes reações de ciúmes, às quais os pais atribuem a causa dos seus comportamentos atuais. Esse fato é investigado com mais detalhes. No ato da sessão, a Sra. Bel relata que Dominique está fixado no pai. Dolto solicita informações sobre a Sra. Bel e seu marido, seus pais, irmãos e cunhados e sobre os irmãos de Dominique (Dolto, 1981, pp.18-31).

O primeiro recurso utilizado por Dominique foi a modelagem. Enquanto sua mãe e Dolto realizaram a entrevista, ele ficou na sala de espera. Entrou para falar com Dolto, sozinho, levando o que havia produzido. A psicanalista, após apresentar-se, questiona se o garoto tem alguma coisa a dizer-lhe. Ele responde que às vezes pensa que viveu uma história verdadeira, e complementa dizendo que "Pensava estar na sala, quando era pequenino, tinha medo de ladrões, eles podem levar o dinheiro, podem levar as pratas... você sabe lá tudo o que eles podem levar!” (Dolto, 1981, p.31). Dolto pensa consigo: A Sala, que em francês é $L a$ Salle não poderia ser $L a$ Sale $=$ A Suja? E então diz para Dominique: Ou então a sua irmãzinha? Dominique então se surpreende com o fato de que ela "sabe tudo"; ao que Dolto responde: "Eu não sei nada de antemão, mas é porque você me diz coisas com suas palavras e eu escuto o 
melhor possível. Você é que sabe o que aconteceu, não eu. Mas juntos talvez possamos compreender tudo direitinho" (Dolto, 1981, p.31).

Dolto, com essa intervenção, delimita que o papel dela ao atendêlo não é o mesmo que os médicos tiveram até então, nem o papel de cuidadora como o da mãe do menino, ou o de professora. Dolto (1981) complementa expondo o seu papel ao dizer para Dominique:

para mim tanto faz, essa história de contas na escola não me interessa ... o que é importante na vida não é o que você faz com as lições, os cadernos e os livros de aula, mas tudo o que se passa no seu coração e que você não quer dizer (Dolto, 1981, p. .32)

Dolto insere o pai no acompanhamento com Dominique, expondo ao menino e à mãe que não poderá atendê-lo sem o consentimento do pai. Nessa primeira sessão já se encontra a distinção do papel de Dolto no trabalho com Dominique, tanto pelo que explicou, quanto pelo que atuou ao interpretar o que ele the disse.

$\mathrm{Na}$ segunda sessão, o pai comparece e concorda com o tratamento psicoterápico. $\mathrm{Na}$ terceira sessão Dolto não faz contato com nenhum adulto antes de atender Dominique, e o pega pela mão para que decida acompanhá-la. Ela retoma o contrato terapêutico, dizendo que nas sessões ele diria tudo o que pensava e os sonhos de que se recordasse, com palavras, desenhos e modelagens, assegurando também o segredo profis- 
sional. Ele começa então a falar sobre Fifi Pulso de Aço, que é forte, corajosa, gentil. No final da sua fala, relata:

e depois eu tinha medo da noite, eu não queria me deitar antes do fim porque quero vêla outra vez, é sobre mim que ela vai agir [longo silêncio e Dominique continua] ... digamos que ela voltou de férias e que está um pouco bronzeada (Dolto, 1981, p.49),

o que de fato acontecera, a psicanalista estava mais bronzeada do que na última vez em que se viram. Dominique expressa o seu entendimento do papel da psicanalista e verbaliza então que este é o espaço e esta é a pessoa que vai trabalhar com ele, demonstrando adesão à figura do analista e ao processo analítico que está acontecendo.

$\mathrm{Na}$ sessão seguinte, assim que entra na sala de Dolto, Dominique diz: "Quero fazer um cão pastor. Você sabe, Pulso de Ferro, acabei com a história dela" (Dolto, 1981, p. 55), e conta uma história sobre um cão que o pai não quis e mandou embora numa caixa num caminhão, mas que com um solavanco, ele caiu, chegou até a estação e perguntou sobre o caminho, e um rapaz que se chama Paulo disse ao pai que, ainda que ele tenha querido se desfazer do cão, ele havia voltado. Dolto faz a relação dessa história com uma outra vivida por Dominique, em que ele se perde ao voltar da escola, vai parar numa estação e volta para casa sozinho, o que não acontecia, visto que o irmão sempre o acompanhava. Irmão que se chama Paul-Marie, mas que às vezes a família chama de Paulo. Dolto escuta, e não fala da semelhança das histórias para Dominique, que continua: "é claro, o princípio do adestramento falhou, mas se uma pessoa se empenhar a fundo e tiver êxito, corre-se o risco de ser premiado. No ano seguinte, poderá tomar o lugar de um outro" (Dolto, 1981, p.58). Notemos que ele diz 'se uma pessoa' e não 'se um animal, que é do que realmente trata um adestramento, aludindo a si próprio, tomando o lugar do irmão, ao qual já havia nominado na história do cão. Dito isso, ficou em silêncio, e quando voltou a falar, foi sobre PaulMarie.

Dominique diz então que o cão que está modelando teve um sonho de se transformar em vaca. Porém, ao falar novamente da vaca, chama-a de boi, demonstrando certa confusão entre as figuras feminina e masculina, o que faz com que Dolto intervenha: "em que idade você soube que o que as vacas têm entre as pernas não era 'faz pipi'?" (Dolto, 1981, p. 59). Essa pergunta dá abertura para que Dominique fale para além dos conteúdos referentes à diferença sexual. O menino diz que soube dessas diferenças muito tarde, diz que touros são maus e esta vaca, a que ele está modelando, é de uma vaca sagrada que pensa ser um boi sagrado. Dolto diz: "Eu creio que o boi sagrado ou a vaca sagrada talvez sejam por causa do carinho especial que você sente por Madame Dolto. Você quer torná-la 
sagrada .... E talvez você já tivesse tido um carinho parecido por outra pessoa?" (Dolto, 1981, p. 59). Ruborizando, Dominique diz que sim, pela sua professora, mas que não pode amar ninguém além de seus pais. Dolto explica-lhe então que ele pode amar outras pessoas, além de seus pais, e que esse amor é diferente de amar outras pessoas ou mulheres, e que um amor não elimina outro, e que mais tarde, depois de se enamorar, ele encontrará alguém de quem ficará noivo, com quem se casará e terá filhos, como aconteceu com seus pais. $\mathrm{O}$ menino ouve atentamente, e quando Dolto termina ele diz: "Ah, bom! Puxa, minha vaca acordou... e afinal de contas ela não é sagrada. É como todas as outras vacas" (Dolto, 1981, $\mathrm{p}, 60)$. Ele continua dizendo que a vaca teve um sonho, e assim dá início a uma nova história. Nesse momento fica clara a utilização da transferência pela analista para trabalhar sobre o sentimento de Dominique, e a confusão e o impedimento que existiam nele com relação a amar outras pessoas além dos pais.

A partir da quinta sessão o discurso de Dominique começa a ficar mais organizado, ele fala de suas angústias, do irmão Senhor-Eu-Sei-Tudo e ele faz alusões a relações eróticas com meninos. Enquanto isso modela um boneco, modela o pênis e coloca duas bolas de massa de modelar no lugar dos seios, dizendo que isso também é o sexo do homem. A psicanalista explica que isso não é o sexo do homem, mas sim o que ele havia colocado no boneco há pouco, o pênis. Notemos que a questão da confusão na diferença sexual é algo que Dominique repete constantemente. Nesse mesmo dia Dominique fala que o irmão gostaria de conversar com Dolto, que ele ficaria contente se isso ocorresse, e que preferiria não estar presente durante a conversa.

Entre outros assuntos, é com Paul-Marie que Dolto descobre que Dominique e Sylvie dormem com sua mãe, mas que ele próprio não gosta de ir para lá. Ao concluir sua conversa com Paul-Marie, chama Dominique para falar-lhe novamente. Expõe o que seu irmão tinha dito sobre a mãe gostar muito de se aquecer tendo-os na cama. Dominique muda o foco da conversa, falando então de seu camarada, que é muito 'gozado'. Dolto interpreta pelo aspecto sexual e diz isso ao garoto, que por sua vez confirma que se divertem com seus corpos, como as vacas fazem com os pipis delas. Novamente Dolto explica sobre o sexo dos homens, e sobre a alteração que há no órgão genital, conforme o que ele sente no seu corpo quando se diverte com ele. Essa explicação dá abertura para que Dominique diga que não deseja mais dormir com sua mãe, que isso era quando ele tinha sete anos, e que hoje isso o deixa esquisito. Dolto então explica-lhe, em termos simples, a proibição do incesto. Ao mesmo tempo não culpa a mãe por pedir que o garoto durma com ela e se sinta dese- 
jando-a. Explica que Dominique é que tem toda a razão de não querer dormir com ela.

Após falar com Dominique, a Sra. Bel pergunta a Dolto se ela ainda tem algo a dizer. Dolto responde que sim, e antes de concordar pergunta a Dominique se ele acredita que seria bom ela conversar com sua mãe. Ele concorda. Dolto não faz rodeios, e diz que a ausência do Sr. Bel incomoda muito os rapazes. Acrescenta que Paul-Marie não está envergonhado quando diz que não quer intimidades com a mãe, mas sim que essa atitude tem um ar inteiramente normal. A Sra. Bel relata que realmente não tem pudor nenhum ao dormir com os filhos ou mostrar-se nua para eles. Com relação aos filhos dormirem com a mãe, Dolto expõe que é preciso que ela aceite esse fato, porém ao falar de Sylvie, ela não compreende. A conclusão da analista, após esta sessão, é que descobriram na mãe uma sexualidade infantil e que a possibilidade do incesto é a causa principal das perturbações de Dominique. É nesse momento também que constatamos o que Cifali (1989, p.65) aborda sobre "uma criança herdeira de nossas dívidas de adultos, uma criança sintomática do que permaneceu atado às gerações que a precederam”, já que, segundo Dolto, a relação com a mãe sexualmente infantil é a causa principal da desorganização em que o garoto de se encontra.

Através desses recortes das sessões iniciais do tratamento psicanalí- tico de Dominique, podemos fazer a seguinte análise. No que diz respeito ao trabalho com os pais no atendimento de Dominique, constatamos que foi a mãe que manteve maior intercâmbio com a psicanalista. Logo no início foi ela quem fez a demanda de atendimento, necessitando que Dolto chamasse o Sr. Bel para dar sua aprovação. Ainda nas primeiras sessões ela manda várias cartas a Dolto para informar sobre o estado de Dominique, para pedir-lhe um documento e assim facilitar o processo de aceitação de Dominique na escola. Após a primeira sessão em que Dolto entrevista a mãe, e a segunda em que o pai esteve presente, a psicanalista iniciou os atendimentos de Dominique na ausência de seus pais, solicitandoos somente quando aprovada por Dominique, como no momento de falar sobre o fato de dormirem com a mãe. No atendimento de Dominique, algumas faltas foram ocasionadas pelo desejo da mãe, como expõe Dolto na descrição da quinta sessão que ocorreu após duas faltas consecutivas. Dolto fez duas intervenções dirigidas aos pais: convocou o pai para participar do processo e interditou a mãe de dormir com os filhos.

Os recursos ofertados no atendimento psicanalítico de Dominique consistiram em desenho, conversação e modelagem, sendo que a modelagem foi utilizada nas cinco primeiras sessões citadas nesse trabalho, e o desenho apenas na segunda. Todos os recursos foram meios que propicia- 
ram a apresentação das questões de Dominique e a elaboração das mesmas com o acompanhamento da analista.

O manejo da transferência pode ser verificado, neste recorte, principalmente no momento em que Dominique fala de sua afeição por Dolto com sua modelagem sobre a vaca sagrada, na credibilidade que atribui ao que Dolto lhe transmite sobre a diferenciação dos sexos e a proibição do incesto, e na confiança que deposita ao permitir que a analista converse com sua mãe sobre o fato de Dominique não querer mais aquecê-la na cama. Nota-se a sutileza com que Dolto se apresenta no processo, embora não se furte a reconhecer cada situação que lhe é dirigida transferencialmente.

As situações de interpretação acontecem desde o apontamento sobre os significantes, como no caso em que Dominique diz La Salle, e Dolto remete a La Sale - A suja-irmã Sylvie, até os momentos de interpretar que o conhecimento de Dominique sobre a diferenciação sexual não existia, fazendo as intervenções para explicarlhe sobre isso. Nestes momentos podemos nos questionar sobre a função desta intervenção: seria ela pedagógica, no sentido de ensinar novos conteúdos? Concluímos que sim, mas o efeito buscado com esses ensinamentos é o de reorganização psíquica, para que através do que está sendo transmitido Dominique possa tomar, por exemplo, a posição de filho, o que o impede de dormir com sua mãe, e, nesse sentido, impede a mãe de pedir que o filho a atenda nesta demanda. Essa interdição é fundamental para a melhora de Dominique, já que, como constatado por Dolto, a possibilidade concreta do incesto estaria no cerne das perturbações do garoto. Ao mesmo tempo, Dolto tem o cuidado de relativizar suas intervenções, atribuindo-as à sua escuta da fala do próprio paciente.

\section{Considerações finais}

Através do trabalho teórico e clínico expostos, destacamos a coerência dos pressupostos básicos da análise com crianças de Françoise Dolto: o trabalho com os pais, a participação na análise de seus filhos e a preocupação de Dolto em estabelecer um sentimento de confiança para que os pais aderissem ao tratamento de seus filhos; a substituição do método da associação livre pela oferta de materiais expressivos, em que a autora se utiliza de modelagens, desenhos e da boneca-flor para conversar com seus pacientes e a adaptação da oferta desses recursos de acordo com a necessidade de cada um; as situações de interpretação, que por muitas vezes consistiu em incentivar seus pacientes a falar, calando-se e deixando com que eles se expressassem, bem como na capacidade de ouvir as crianças em lugar de falar por elas. 
$\mathrm{Na}$ análise com crianças proposta por Françoise Dolto, o analista tem um papel ativo, no sentido de questionar e também elucidar conteúdos fundamentais para a constituição subjetiva, visando uma reorganização psíquica, como ocorreu com Dominique, quanto à diferenciação das figuras masculina e feminina, sobre o ato sexual, e sobre a proibição do incesto. Frente a essa confusão apresentada por Dominique, Dolto explicoulhe estes conteúdos, bem como enunciou a proibição do incesto com a mãe, que solicitava que os filhos dormissem com ela. Outro exemplo da atividade envolvida na clínica de Dolto se dá logo no início do atendimento de Bernadette, quando a mãe precisa se ausentar e Dolto insere essse assunto na análise da menina, questionando o que ela estava pensando sobre isso.

As intervenções de Dolto não têm como característica comunicar algo ao paciente sobre o que ele fala, mas sim, instaurar uma escuta analítica fina que permita falar de determinado assunto. Quando Dominique lhe diz que pensava estar na sala (la salle) com receio de que um ladrão o assaltasse, Dolto escutou analiticamente, a partir da homofonia das palavras, supondo que ao falar la salle (a sala) ele queria referir-se à la sale (a suja),e sua interpretação dessa manifestação do inconsciente foi perguntar "ou então sua irmãzinha?” (Dolto, 1981, p.31).
Outro ponto que ressaltamos nesses casos é a posição de acolhimento da analista ao aceitar as crianças em análise, não as culpando, não consentindo com o seu comportamento, nem tampouco tentando lhes ensinar novos comportamentos, mas orientando as sessões com os materiais que elas produziam.

É importante ressaltar a posição de Dolto em não realizar interpretações diretas das produções realizadas com os recursos ofertados. Ela atuava muito mais orientando as conversações surgidas através desses recursos e tentando produzir nas crianças discursos variados sobre suas dificuldades e conflitos.

Além de focar no dito de seus pacientes, Dolto preocupava-se em "escutar, olhar, observar, sem deixar escapar o mínimo detalhe, os gestos, as expressões, a mímica, palavras, lapsos, erros e desenhos espontâneos", (Dolto, 1988, pp.132-133); do mesmo modo como aconteceu com Bernadette quando recebeu a boneca-flor e demonstrou além da fala sua aceitação desse recurso. Esses pressupostos teóricos apresentados por Dolto aparecem em sua clínica, sendo então sua prática coerente com sua teoria.

Da transmissão de Dolto, destacamos todos os conteúdos abordados nessa pesquisa, a maneira como concebe a criança, como trabalha com ela e com os pais, a capacidade de compreender as dificuldades da criança e de trabalhar com elas, bem como os 
rompimentos que a analista faz ao entender a criança como um ser autônomo e responsável, e ao tratar a criança juntamente com a família, utilizando métodos expressivos coerentes com a sua condição.

Enfim, para concluir, podemos afirmar que Françoise Dolto foi uma psicanalista única, com uma prática singular, decorrente de um estilo próprio. $\mathrm{O}$ que ela propõe ao falar do trabalho do psicanalista, e o lugar que dá à criança e aos pais nos seus escritos e nas suas palestras, são coerentes com o que se pode conhecer do relato de sua prática. Nesse sentido, trata-se de uma psicanalista admirável, cuja obra vale a pena conhecer, não para tentar imitá-la - o que seria impossível -, mas para tomar como exemplo sua postura ética e criativa diante da criança e da psicanálise.

THE FRANCOISE DOLTO'S PSYCHOANALYTICAL PRACTICE THRU THEIR CLINIC CASES

\begin{abstract}
This article is about Francoise Dolto works and theory. The objectives comprehend the basics themes of her theory; characterize the interventions of the psychoanalyst in the children's analysis; and exemplifying her methods through the main interventions made in Dominique Case and Bernadette Case. As result, we can see in the how Dolto worked with total knowledge the phenomena of transference and the situations of interpretation; how provided the offer of right sources to the children's condition; how leaded the work with the parents in the way of allow them to effective the felling of trust on them and add the analytic treatment of their children.
\end{abstract}

Index terms: psychoanalysis for children; Françoise Dolto; transference; interpretation; work with parents.

LA PRACTICA PSICOANALÍTICA DE FRANCOISE DOLTO A PARTIR DE SUS CASOS CLÍNICOS

\title{
RESUMEN
}

Este artigo se basa en el trabajo y teoría de Françoise Dolto. Tuvimos como objetivo entender los supuestos básicos de su teoría; caracterizar las intervenciones de los psicoanalistas en el análisis con niños; y ejemplificar su método a través de los cortes de las principales intervenciones realizadas en el Caso Dominique y en el caso Bernadette. Como resultado, constatamos que Dolto trabajaba con dominio el fenómeno de la transferencia y las situaciones de interpretación; proporcionaba la ofrenda de recursos adecuados a las condiciones de los niños; llevaba el trabajo con los padres permitiendo la efectuación del sentimiento de confianza en ellos, en unirse al tratamiento analítico de sus hijos. 
Palabras clave: psicoanálisis con niños; Françoise Dolto; transferencia; interpretación; trabajo con padres.

\section{REFERÊNCIAS}

Bernardino, L. M. F. (2004). O desejo do psicanalista e a criança. In L. M. F. Bernardino (Org.), Psicanalisar crianças: que desejo é esse? (pp.57-70). Salvador: Ágalma.

Cifali, M. (1989). Da hipnose à escuta. In M. Cifali, Seguindo os passos de Françoise Dolto (B. Sidou, trad., pp.47-69). Campinas, SP: Papirus.

Dolto, F. (1980). Prefácio. In M. Mannoni. Primeira entrevista em psicanálise $\left(3^{\mathrm{a}}\right.$ ed., p. 14). RJ: Campus.

Dolto, F. (1981). O caso Dominique (A. Cabral, trad., 2a ed.). Rio de Janeiro: Zahar.

Dolto, F. (1988). Psicanálise e pediatria (A. Cabral, trad., 4a ed.). Rio de Janeiro: Guanabara-Koogan. (Trabalho original publicado em 1971)

Dolto, F. (1996). No jogo do desejo (V. Ribeiro, trad., 2a ed.). São Paulo: Ática.

Dolto, F., \& Roudinesco, E. (1989). Elementos para uma história. Uma conversa. In M. Cifali. Seguindo os passos de Françoise Dolto (B. Sidou, trad., pp.9-36). Campinas, SP: Papirus.

Dolto, F., \& Nasio, J-D. (2008). A criança do espelho (A. Telles, trad.). Rio de Janeiro: Zahar.

Freud, A. (1971). Tratamento psicanalítico de crianças. Rio de Janeiro: Imago.

Freud, S. (1996a). Explicações, Aplicações e Orientações. In S. Freud, Edição standard brasileira das obras psicológicas completas de Sigmund Freud (J. Salomão, trad., Vol. 22, pp. 135-154). Rio Janeiro: Imago. (Trabalho original publicado em 1933)

Freud, S. (1996b). Carta 105. In S. Freud, Edição standard brasileira das obras psicológicas completas de Sigmund Freud (J. Salomão, 
trad., Vol. 1, pp. 329-331). Rio Janeiro: Imago. (Trabalho original publicado em 1899).

Freud, S. (1996c). Inibições, sintomas e ansiedade. In S. Freud, Edição standard brasileira das obras psicologicas completas de Sigmund Frend (J. Salomão, trad., Vol. 20, pp. 79-171). Rio Janeiro: Imago. (Trabalho original publicado em 1926)

Guirado, M. (1995). Psicanálise e análise do discurso. Matrizes institucionais do sujeito psíquico. São Paulo: Summus.

Halmos, C. (1989). Entre as crianças e os psicanalistas. In M. Cifali, Seguindo os passos de Françoise Dolto (B. Sidou, trad., pp.73-103). Campinas, SP: Papirus.

Klein, M. (1969). Psicanálise da criança. São Paulo: Mestre Jou.

Klein, M. (1981). Contribuições à psicanálise (M. Maillet, trad.). São Paulo: Mestre Jou.

Mannoni, M. (1986). De um impossivel a outro (V. Ribeiro, trad.). Rio de Janeiro: Zahar.

Mannoni, M. (1999). A criança, sua doença e os outros. São Paulo: Via Lettera.

Winnicott, D. W. (1984). Consultas terapêuticas em psiquiatria Infantil (J. M. X. Cunha, trad.). Rio de Janeiro, Imago.

vanisoler@yahoo.com.br

Rua 24 de Maio, 145

84500-000 - Irati - PR - Brasil.

ledber@terra.com.br Av. Batel, 1920/210

80420-090 - Curitiba - PR - Brasil. 